• 研究报告・

\title{
桂西南喀斯特季节性雨林叶凋落量的时空动态
}

\author{
贾梦可 $1,2,3$ 郭屹立 ${ }^{1,3^{*}}$ 李冬兴 ${ }^{1,3}$ 王 斌 1,3 向悟生 ${ }^{1,3}$ 王爱龙 ${ }^{4}$ \\ 刘是源 4 丁 涛 1,3 黄甫昭 1,3 文淑均 1,3 陆树华 1,3 李先琨 $1,3^{*}$
}

1 (广西壮族自治区中国科学院广西植物研究所广西喀斯特植物保育与恢复生态学重点实验室, 广西桂林 541006)

2 (广西师范大学生命科学学院, 广西桂林 541006)

3 (广西友谊关森林生态系统国家定位观测研究站, 广西凭祥 532699)

4 (广西弄岗国家级自然保护区管理中心, 广西龙州 532400)

摘要: 森林调落物是森林生态系统极其重要的组成部分, 关系着森林生态系统的物质循环和养分平衡。然而, 有 关异质性自然森林生态系统中生物与非生物因子对调落物调落量的影响机制还存在较大争议。本文以广西弄岗15 ha森林动态监测样地中设置的90个调落物收集器所收集的调落叶为研究对象, 选取2013-2018年连续6年的调落叶 数据探讨了森林叶调落量的时空动态, 旨在深入了解该地区森林生态系统的物质循环过程及调落量的影响因子。 结果显示: 2013-2018年的年均叶调落量为4,099.44 kg/ha, 标准误为232.34, 变异系数为 0.15 , 这表明不同年际间叶 调落量存在明显差异; 不同年际间叶调落量的节律性变化为双峰型、三峰型或多峰型, 说明不同年份的叶调落量 存在明显的节律性差异, 但总体而言高峰期主要出现在每年的春季(3-4月)和秋季(8-10月); 生态因子对叶调落量 年际动态存在显著影响, 其累计解释率为 $69.3 \%$, 其中海拔对叶调落量的影响最强, 解释率为 $46.5 \%$; 而生物因子 如胸径变异系数、单位面积胸高断面积之和和物种丰富度则对叶调落量的影响较弱。多年的连续监测表明, 喀斯 特季节性雨林不同年际间叶片的调落量和节律性存在显著差异, 而非生物因子, 如海拔是形成叶调落量空间变异 的主要因素。

关键词：喀斯特季节性雨林; 叶调落量; 年际差异; 节律性; 生态因子

\section{Spatio-temporal dynamics of leaf litter in a karst seasonal rainforest in southwest Guangxi}

Mengke $\mathrm{Jia}^{1,2,3}$, Yili Guo ${ }^{1,3^{*}}$, Dongxing $\mathrm{Li}^{1,3}$, Bin Wang ${ }^{1,3}$, Wusheng Xiang ${ }^{1,3}$, Ailong Wang ${ }^{4}$, Shengyuan $\mathrm{Liu}^{4}$, Tao Ding ${ }^{1,3}$, Fuzhao Huang ${ }^{1,3}$, Shujun Wen ${ }^{1,3}$, Shuhua $\mathrm{Lu}^{1,3}$, Xiankun $\mathrm{Li}^{1,3^{*}}$

1 Guangxi Key Laboratory of Plant Conservation and Restoration Ecology in Karst Terrain, Guangxi Institute of Botany, Guangxi Zhuang Autonomous Region and Chinese Academy of Sciences, Guilin, Guangxi 541006

2 College of Life Sciences, Guangxi Normal University, Guilin, Guangxi 541006

3 Guangxi Youyiguan Forest Ecosystem National Research Station, Pingxiang, Guangxi 532699

4 Administration of Nonggang National Nature Reserve of Guangxi, Longzhou, Guangxi 532400

\begin{abstract}
Leaf litter production is a major contributor to ecosystem net primary productivity and biogeochemical cycles. However, various abiotic and biotic drivefteence leaf litter production in heterogeneous natural forests. In this study, we quantified leaf litter production, composition, and spatio-temporal dynamics in a 15 ha forest dynamics plot in Nonggang National Nature Reserve, Guangxi. We set up 90 litter fall traps and collected leaf litter weekly beginning in May 2012. We explored the spatial and temporal dynamics of leaf litter production in order to gain an in-depth understanding of the material circulation process of forest ecosystem in this region. Ecological factors had significant influence on the inter-annual dynamics of leaf litter volume and explained $69.3 \%$ of the cumulative deviation. The effect of altitude on leaf litter was the strongest, explaining $46.5 \%$ of the deviation. However, biological factors, such as the coefficient of variation of DBH, the sum of stand basal area per unit area, and species-richness, had
\end{abstract}


smaller effect sizes on annual leaf litter production. Years of continuous monitoring show that there are obvious differences in the leaf litter production between years in karst seasonal rainforests, but abiotic factors, such as altitude, heavily influence leaf litter production.

Key words: karst seasonal rainforests; leaf litter production; annual difference; rhythmicity; ecological factors

调落物是森林生态系统极其重要的组成部分, 在促进森林生态系统物质循环、能量流动和养分平 衡及减少水土流失和维持生态系统功能方面具有 关键作用(Vasconcelos \& Luizao, 2004; Han et al, 2007)。森林调落量是单位面积单位时间上林地所有 调落物的总量, 它能间接反映森林生态系统的初级 生产力水平, 如热带森林生态系统中调落物占初级 生产力的41\%左右(Malhi, 2012)。调落物的动态变化 是指凋落量在时间和空间上的变化,一般分为季节 性动态变化和年际动态变化, 是森林调落物研究的 重要内容之一。局域尺度上, 生物与非生物因子均 会影响调落物的形成, 而二者对调落物形成的重要 性还存在较大争议(Guo et al, 2019)。目前, 有关森 林调落量及其动态的研究已有大量报道, 而针对某 一地区调落物连续多年的动态监测还比较少见。

中国西南喀斯特区是全球最大的喀斯特连续 分布带(Yuan, 1991)。喀斯特生态系统中, 由于基岩 出露面积大, 又长期受溶蚀及风化作用影响, 地表 形成了错综复杂的溶沟、岩缝、石脊、裸露岩石等 微环境结构(蒋忠诚和袁道先, 1999; 李先琨等, 2008; 郭柯等, 2011)。喀斯特环境本身的脆弱性加 上人类活动的过度干扰, 导致我国西南喀斯特地区 森林土壤贫痊、水土流失严重, 产生了以石漠化为 特征的生态环境退化(曹坤芳等, 2014)。以往有关喀 斯特森林生态系统调落量的相关工作均为小尺度 上选择不同群落类型开展的短时间研究, 存在调落 物收集年限短且调落节律无重复性, 缺乏长期定位 监测等问题。国际统一标准下建立的弄岗 $15 \mathrm{ha}$ 森林 动态监测样地为揭示该地区森林调落物动态与机 制的普遍性和特殊性规律提供了研究平台。

本文以广西南部典型季节性雨林喀斯特地质 背景下的弄岗 15 ha森林动态监测样地为研究平台, 以样地内布设的 90 个调落物收集器所收集的调落 物为研究对象, 分析了 2013-2018年调落物的年际 动态变化及其影响因素。由于调落物中枝条的调落 存在偶然性和不确定性, 因此本研究仅以调落叶作
为研究对象。其目的是：(1)探讨喀斯特季节性雨林 叶调落量的年际变化规律和季节性节律; (2)分析喀 斯特季节性雨林中调落叶与生态因子的相关性, 揭 示影响叶调落量的主要控制因子; (3)为进一步揭示 喀斯特季节性雨林年净初级生产力及其时空分布 格局与形成机制等深层次研究提供参考。

\section{材料与方法}

\section{1 研究地概况}

弄岗国家级自然保护区位于广西龙州县以东、 宁明县以北 $\left(106^{\circ} 42^{\prime} 28^{\prime \prime}-107^{\circ} 04^{\prime} 54^{\prime \prime} E ， 22^{\circ} 13^{\prime} 56^{\prime \prime}-\right.$ $22^{\circ} 39^{\prime} 09^{\prime \prime} \mathrm{N}$ ), 是典型的北热带季节性雨林喀斯特 地貌, 地形上以典型的喀斯特峰从洼陷为特征, 其 地质主要由多孔石灰岩组成, 有许多坑洞、洞穴和 广泛的地下溪流。保护区洼地底部海拔为150-200 m 左右, 洼地最大深度为 $114 \mathrm{~m}$, 最大宽度为 $450 \mathrm{~m}$ 。 该区域地表水缺乏, 而地下水通道丰富, 形成了复 杂的地下河系, 其枯水期(12月至翌年2月)最低水位 埋深在 5-25 m, 丰水期(5-7月)最高水位则高于地 面0-3 $\mathrm{m}$ 。保护区年平均气温为 $22^{\circ} \mathrm{C}$, 最冷月平均气 温在 $13^{\circ} \mathrm{C}$ 以上, 每年有 7 个月的月平均温度在 $22^{\circ} \mathrm{C}$ 以 上, 年均降水量为 $1,150-1,550 \mathrm{~mm}$, 最高达 $2,043 \mathrm{~mm}$, 最少为 $890 \mathrm{~mm}$, 其中 76\%的降水量集中在 5-9月 (Guo et al, 2018, 图1)。

依照CTFS (Center for Tropical Forest Science) 样地建设标准(Condit, 1998), 广西壮族自治区中国 科学院广西植物研究所于2011年在弄岗国家级自 然保护区建立了 15 ha森林动态监测样地。该样地东 西长500 m, 南北长 $300 \mathrm{~m}$, 海拔范围在180-370 m 之间。样地植物群落结构复杂、物种组成丰富, 具 有很高的生境异质性, 包含了一系列典型的“峰从一 洼地”生境类型, 具有喀斯特地质背景的典型性与 代表性。2011年第一次调查发现样地内DBH $\geq 1 \mathrm{~cm}$ 的木本植物有 223 种, 隶属于 56 科 157 属, 独立个体 68,010株。主要优势种有闭花木(Cleistanthus sumatranus)、莬华 (Sterculia monosperma)、广西牡荆(Vitex 


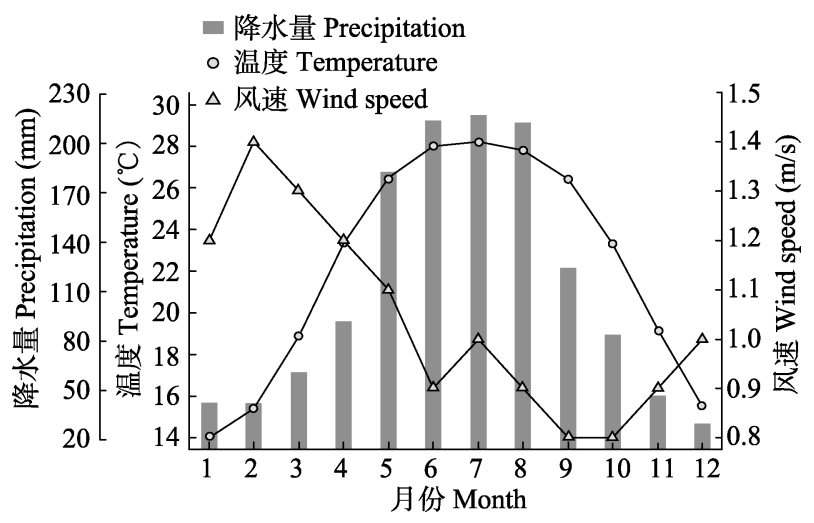

图1 广西龙州县2000年1月至2015年12月月平均降水量、风 速、气温的变化

Fig. 1 Monthly variations of mean precipitation, wind speed and air temperature between January 2000 and December 2015 in Longzhou County, Guangxi

kwangsiensis)等(王斌等, 2014)。

\section{2 研究方法}

\subsection{1 凋落物收集器布设方案}

依据样地地形和群落等特征, 于2012年5月在 弄岗 $15 \mathrm{ha}$ 森林动态监测样地中布设了 90 个调落物 收集器(图2)。其设置原则为: (1)能代表样地内所有 的群落类型和生境类型; (2)基本保证同一株母树的 调落物不会自然调落到两个收集器内, 即根据树种 冠幅, 样地内两个收集器之间的距离不小于 $10 \mathrm{~m}$; (3)为避免边缘效应, 同时也尽可能地保证凋落物都 来自于样地内母树, 样地边缘 $20 \mathrm{~m}$ 内不设置收集器 (Du et al, 2009)。由于喀斯特地貌地形复杂, 实际操 作中并不能严格按照上述规定架设调落物收集器, 只能尽可能地选择合适的地点。如峰顶及其周边高 坡位地区地形陡峭, 仅分布有大量的芸香竹(Bonia saxatilis), 而木本植物分布较少, 因此未布设调落 物收集器(郭屹立等, 2017; Guo et al, 2019)。

\subsection{2 调落物采样设计}

结合弄岗北热带喀斯特季节性雨林的气候特 征, 于每月月中和月末各收集1次, 如遇大风、降雨 等不适合野外工作的天气则适当推迟收集日期。每 次收集的调落物以收集器为单位进行编号, 按花、 果实、枝干 (直径 $<2 \mathrm{~cm}$ )、叶片及其他杂物进行分 类, 并对叶片和果实进行物种鉴定。在 $80^{\circ} \mathrm{C}$ 烘箱中 烘干至恒重(连续烘 $48 \mathrm{~h}$ 以上)后, 用精度为 $0.01 \mathrm{~g}$ 的 电子天平称重, 记录凋落物收集器编号、收集日期、 各组分重量等信息。依据CTFS标准, 藤本植物和竹 亚科植物未纳入研究范围(Guo et al, 2019)。

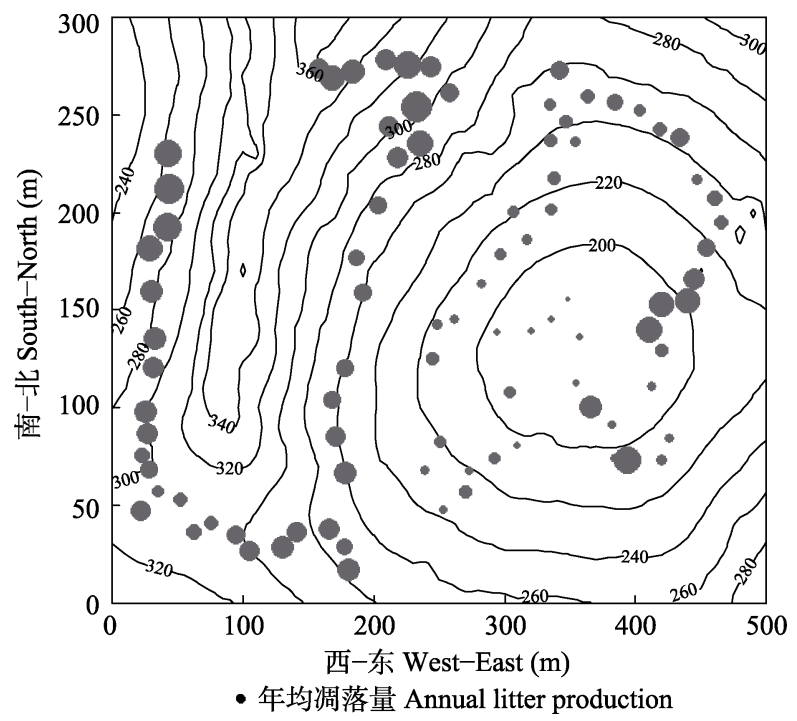

图2 弄岗15 ha森林动态监测样地等高线图及90个凋落物 收集器的多年叶片年均凋落量。圆点大小代表凋落量的多少。 Fig. 2 The contour map and perennial annual leaf litter fall production of 90 litter fall traps of the 15 ha forest dynamics plot in Nonggang, Guangxi. Black dots size indicate the production of litter fall.

\section{3 数据分析}

以2013-2018年连续6年收集的调落物为研究 对象, 分析不同年际的调落物动态及不同生态因子 (环境因子和生物因子)的影响。其中, 环境因子为调 落物收集器所在 $10 \mathrm{~m} \times 10 \mathrm{~m}$ 样方的平均海拔、凹凸 度、坡度、坡向、地形湿润度指数和干旱度指数等。 有关环境因子的计算方法参考郭屹立等(2015)。生 物因子则基于 2016 年弄岗 15 ha样地的复查数据, 包括以调落物收集器为圆心, $5 \mathrm{~m}$ 为半径的圆形样 方内所有胸径 $\geq 1 \mathrm{~cm}$ 植株的胸径变异系数、胸高断 面积之和、物种丰富度等(Guo et al, 2019)。其中，单 位面积样方内所有个体胸径的变异系数 $\left(D B H_{\mathrm{CV}}\right)$ 常 用来作为衡量群落结构多样性的指标:

$$
D B H_{\mathrm{CV}}=\sigma / \mu
$$

其中, $\sigma$ 为单位面积样方内所有个体的胸径的方差, $\mu$ 为胸径的平均值。

本研究选用广义可加模型(generalized additive model, GAM)来检验不同生态因子对调落量的解释 率。广义可加模型常用来处理响应变量与多个解释 变量之间的非线性关系(Guisan et al, 2002), 它通过 连接函数来建立响应变量的数学期望值与预测变 量的光滑函数间的关系(Wood, 2006)。

在广义可加模型参数选择时, 首先确定 90 个调 
落物收集器收集的年均调落量的概率密度分布呈 现近正态分布, 因此连接函数选择identity 函数 (Wood, 2006a)。为检验每一模型的适合度, 对其偏 差系数 $\left(D^{2}\right)$ 进行估算(Swartzman et al, 1992):

$$
D^{2}=(N D-R D) / N D
$$

式中, $N D$ 为空模型偏差, $R D$ 为剩余偏差。 $D^{2}$ 值越接 近1, 说明模型剩余偏差越小, 模型拟合度越好。

利用赤池信息准则(Akaike information criterion, AIC)检验逐步加入生态因子后的模型拟合度, 其值 越小说明模型的拟合效果越好(Burnham \& Anderson, 2002)。利用 $F$ 检验和卡方检验分别评估环境因 子的显著性及其对非参数效果的非线性贡献率。

广义可加模型拟合基于 $\mathrm{R}$ 软件mgcr包中的 gam 函数(Wood, 2006)进行, 所有数据分析和绘图均在 R 3.6.1 (R Core Team, 2019)中实现。

\section{2 结果}

\section{1 叶凋落量年际动态}

2013-2018年调落叶片的年调落量分别为: 4,186.99 kg/ha、3,664.15 kg/ha、3,178.93 kg/ha、 4,198.18 kg/ha、4,363.88 kg/ha和5,004.50 kg/ha, 其 多年变异系数为 0.15 , 表明叶调落量存在明显的年 际间波动(图3)。2013-2018年共鉴定到125种物种的 调落叶，占调落物总量的 $83.6 \%$ 。鉴定出的物种的频 次和调落量与样地中物种的多度有关, 且主要为乔 木层物种, 以闭花木、广西牡荆、苹婆、海南椴 (Diplodiscus trichosperma)、蚬木(Excentrodendron tonkinense)、劲直刺桐(Erythrina stricta)等为主, 而 个别乔木种如白头树(Garuga forrestii)、羽叶楸 (Stereospermum colais) 等则仅出现一次, 且调落量

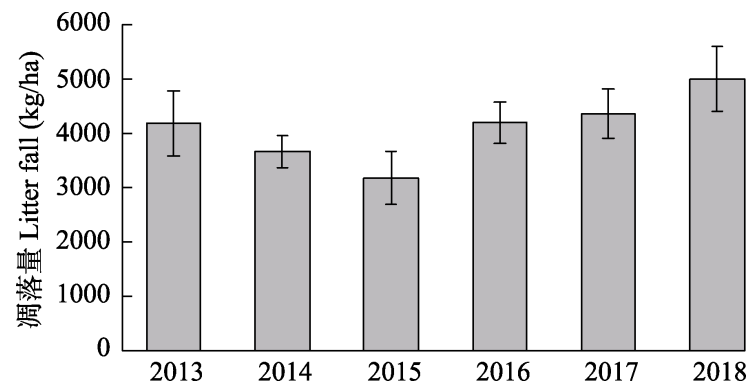

图3 弄岗15 ha森林动态监测样地2013-2018年叶调落量的 年际动态 $($ 平均值 \pm SD)

Fig. 3 Annual dynamics of leaf litter fall production between 2013 and 2018 of the 15 ha forest dynamics plot in Nonggang, Guangxi (mean $\pm \mathrm{SD}$ )
很少。多数灌木层物种未被鉴定出来, 这表明灌木 层物种的调落物较少或者难以被收集器收集到。

\section{2 叶调落量季节性动态}

不同年际间叶片调落量的季节性动态存在明 显差异(图4)。如，2013年叶调落量节律表现为三峰 型曲线波动，具体峰值出现在3月、6月和9月; 2014 年叶调落量节律表现为双峰型，4月出现第一次峰 值，之后急剧下降，并在7月后平稳上升，在9月达 到第二次高峰; 2015年出现多峰型，具体表现为4 月、6月和 9 月出现峰值, 之后下降, 并在11月出现 第4次小高峰; 2016年的叶调落量同样呈现三峰型 曲线波动, 具体表现为 4 月调落量出现第一次峰值, 于7月出现一次小高峰，并于10月再次出现高峰; 2017和2018年叶调落量动态则都呈现双峰型, 峰值 分别出现在4月和9月。虽然叶调落量的多年季节性 动态波动并无稳定的规律, 但其高峰期大致都出现 在每年的春季(3-4月)和秋季(8-11月)，表现为明显 的双峰型。

\section{3 叶调落量动态变化的驱动因子}

对收集器内叶调落总量和生态因子的相关性 分析结果显示，年均叶调落量与海拔、坡度、凹凸 度以及干旱度指数存在显著正相关，而与湿润度指 数及胸径变异系数则存在显著负相关 (表1)。为了检 验不同生态因子对年均调落量的解释率, 本研究采 用逐一获取每个生态因子的广义可加性模型模拟 结果, 发现除物种丰富度外的其他生态因子均对年 均凋落量的解释率表现出显著性, 其中解释率最高 的是海拔, 为 $46.5 \%$; 其次为坡度和湿润度指数, 分

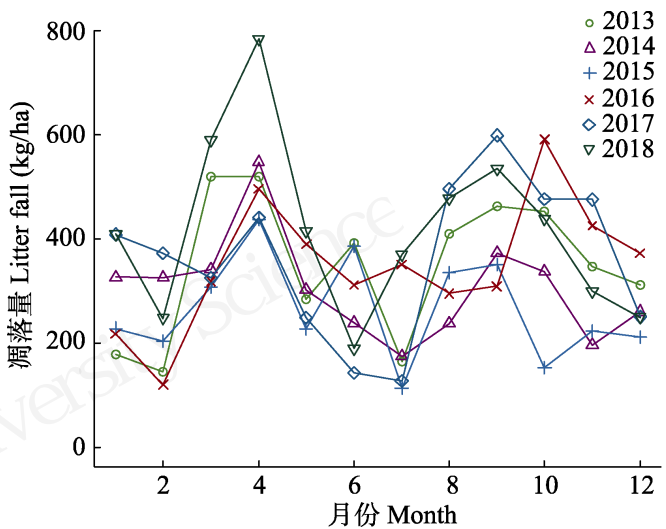

图4 弄岗15 ha森林动态监测样地2013-2018年叶凋落量的 节律性

Fig. 4 Rhythmicity of leave litter fall production between 2013 and 2018 of the 15 ha forest dynamics plot in Nonggang, Guangxi 
别为 $29.1 \%$ 和 $27.2 \%$ (表2); 而解释率最低的为胸径 变异系数, 仅 $5.3 \%$ 。

为了检验所有生态因子对年均调落量的解释 率, 本研究在剔除对调落量的形成并不显著的物种 丰富度指数后, 进一步采用逐步法获得广义可加性 模型模拟结果。该模型对年均调落量的累积解释率 为 $69.3 \%$, 其中贡献最大的为海拔, 解释率为 $46.5 \%$, 而生物因子如胸径变异系数和胸高断面积之和的 解释率则近于零(表3)。

\section{3 讨论}

调落量反映了森林生态系统的初级生产力水平 (Liu et al, 2004), 是森林生态系统功能大小的体现。
弄岗喀斯特季节性雨林在2013-2018年连续6年的 叶年均调落量为 $4099.44 \mathrm{~kg} / \mathrm{ha}$, 低于中亚热带的茂 兰喀斯特森林(4,503 kg/ha) (俞国松等, 2011)和非喀 斯特地质背景的中亚热带阔叶林(8,450-9,000 kg/ha) (官丽莉等, 2004; 阎恩荣等, 2008)。此外, 已有研究 认为热带森林中凋落物占年净初级生产力的 $41 \%$ 左 右(Malhi，2012)，据此估算，北热带喀斯特季节性 雨林年净初级生产力约为 $11.76 \mathrm{t} / \mathrm{ha}$.

有关森林凋落物的月调落量动态的研究已有 很多，且大多与调落节律有关(Sharma et al，2012; Zhang et al, 2014)。森林调落量一般均具有明显的季 节性变化规律, 其季节动态模式有单峰、双峰及不 规则型(王凤友, 1989)。弄岗喀斯特季节性雨林叶片

表1 弄岗15 ha森林动态监测样地不同年际叶凋落量和生态因子间的相关性

Table 1 Correlations between leaf litter fall production and ecological factors in different years of the 15 ha forest dynamics plot in Nonggang, Guangxi. *, $P<0.05$; **, $P<0.01$.

\begin{tabular}{llllllll}
\hline & 2013 & 2014 & 2015 & 2016 & 2017 & 2018 & 平均值 Mean \\
\hline 海拔 Elevation & $0.578^{* *}$ & $0.670^{* *}$ & $0.644^{* *}$ & $0.394^{* *}$ & $0.491^{* *}$ & $0.697^{* *}$ & $0.682^{* *}$ \\
坡度 Slope & $0.447^{* *}$ & $0.400^{* *}$ & $0.421^{* *}$ & $0.422^{* *}$ & $0.314^{* *}$ & $0.255^{*}$ & $0.411^{* *}$ \\
凹凸度 Convexity & $0.276^{* *}$ & $0.223^{*}$ & $0.302^{* *}$ & $0.286^{* *}$ & $0.238^{*}$ & 0.139 & $0.262^{*}$ \\
坡向 Aspect & 0.141 & $0.296^{* *}$ & 0.095 & 0.01 & 0.046 & $0.222^{*}$ & 0.172 \\
岩石裸露率 Rock-bareness rate & $0.183^{*}$ & $0.223^{* *}$ & $0.192^{* *}$ & $0.289^{* *}$ & $0.268^{* *}$ & $0.334^{* *}$ & $0.255^{* *}$ \\
湿润度指数 Topographic wetness index & $-0.461^{* * *}$ & $-0.494^{* *}$ & $-0.509^{* *}$ & $-0.446^{* *}$ & $-0.400^{* *}$ & $-0.363^{* *}$ & $-0.497^{* *}$ \\
干早度指数 Altitude above channel & 0.2 & $0.264^{*}$ & $0.324^{* *}$ & $0.220^{*}$ & $0.343^{* *}$ & $0.294^{* *}$ & $0.316^{* *}$ \\
胸径变异系数 DBH variation & $-0.281^{* *}$ & $-0.352^{* *}$ & $-0.284^{* *}$ & -0.137 & -0.114 & $-0.326^{* *}$ & $-0.299^{* *}$ \\
胸高断面积之和 Total basal area & $0.229^{* * *}$ & $0.218^{* *}$ & $0.229^{* *}$ & $0.243^{*}$ & $0.145^{*}$ & $0.196^{*}$ & $0.234^{* *}$ \\
物种丰富度 Species richness & 0.089 & 0.112 & 0.091 & 0.132 & 0.103 & 0.078 & 0.097
\end{tabular}

表2 弄岗15 ha森林动态监测样地年均叶凋落量分别与不同因子的广义可加模型(GAMs)检验

Table 2 Test of generalized additive models (GAMs) for modeling leaf annual litter fall production of the 15 ha forest dynamics plot in Nonggang, Guangxi with different indices, respectively

\begin{tabular}{llllll}
\hline $\begin{array}{l}\text { 模型因子 } \\
\text { Environmental parameters }\end{array}$ & $r_{\text {adj }}^{2}$ & $\begin{array}{l}\text { 累计解释率 } \\
\text { Cumulative explained } \\
\text { deviation (\%) }\end{array}$ & AIC & $\begin{array}{l}\text { 贡献拟合值 } \\
\text { Fitted contribution } \\
\text { values }\end{array}$ & $\begin{array}{l}\text { 卡方检验 } \\
P_{\mathrm{r}}(\chi)\end{array}$ \\
\hline 海拔 Elevation & 0.425 & 46.5 & 116.366 & 9.344 & 0.000 \\
坡度 Slope & 0.256 & 29.1 & $1,137.742$ & 6.254 & 0.000 \\
凹凸度 Convexity & 0.210 & 25.9 & $1,144.322$ & 4.041 & 0.001 \\
坡向 Aspect & 0.114 & 16.7 & $1,154.586$ & 2.161 & 0.056 \\
岩石裸露率 Rock-bareness rate & 0.171 & 22.8 & $1,149.297$ & 2.848 & 0.008 \\
湿润度指数 Topographic wetness index & 0.257 & 27.2 & $1,135.356$ & 13.75 & 0.000 \\
干旱度指数 Altitude above channel & 0.071 & 8.15 & $1,154.644$ & 7.809 & 0.006 \\
胸径变异系数 DBH variation & 0.042 & 5.32 & $1,157.379$ & 4.943 & 0.029 \\
胸高断面积之和 Total basal area & 0.162 & 22.9 & $1,151.089$ & 2.598 & 0.015 \\
物种丰富度 Species richness & 0.044 & 7.87 & $1,159.372$ & 1.437 & 0.229 \\
\hline
\end{tabular}

$P_{\mathrm{r}}(\chi)$ 表示对非参数平滑效果的非线性贡献检验得分，其值越小效果越好。

$P_{\mathrm{r}}(\chi)$ represented a type of score test to evaluate the non-linear contribution of non-parametric effects, and the lowest value meant the best. 
表3 弄岗15 ha森林动态监测样地年均叶调落量与所有因子的广义可加模型(GAMs)检验

Table 3 Test of generalized additive models (GAMs) for modeling annual leaf litter fall production of the 15 ha forest dynamics plot in Nonggang, Guangxi with all of the indices

\begin{tabular}{|c|c|c|c|c|c|c|}
\hline $\begin{array}{l}\text { 模型因子 } \\
\text { Environmental parameters }\end{array}$ & $r_{\text {adj }}^{2}$ & $\begin{array}{l}\text { 累计解释率 } \\
\text { Cumulative expla- } \\
\text { ined deviation (\%) }\end{array}$ & AIC & $\begin{array}{l}F \text { 检验 } \\
P_{r}(F)\end{array}$ & $\begin{array}{l}\text { 贡献拟合值 } \\
\text { Fitted contri- } \\
\text { bution values }\end{array}$ & $\begin{array}{l}\text { 卡方检验 } \\
P_{\mathrm{r}}(\chi)\end{array}$ \\
\hline 海拔 Elevation & 0.425 & 46.5 & $1,116.366$ & 0.000 & 6.108 & 0.000 \\
\hline 坡度 Slope & 0.458 & 49.2 & $1,110.539$ & 0.000 & 0.025 & 0.874 \\
\hline 凹凸度 Convexity & 0.513 & 57.7 & $1,106.171$ & 0.000 & 1.289 & 0.260 \\
\hline 坡向 Aspect & 0.525 & 58.9 & $1,104.41$ & 0.000 & 2.215 & 0.033 \\
\hline 岩石裸露率 Rock-bareness rate & 0.596 & 67.5 & $1,093.937$ & 0.000 & 2.631 & 0.109 \\
\hline 湿润度指数 Topographic wetness index & 0.602 & 69.3 & $1,094.793$ & 0.000 & 0.887 & 0.349 \\
\hline 干旱度指数 Altitude above channel & 0.593 & 68.1 & $1,095.75$ & 0.000 & 0.821 & 0.368 \\
\hline 胸径变异系数 DBH variation & 0.591 & 68.4 & $1,096.955$ & 0.000 & 0.002 & 0.963 \\
\hline 胸高断面积之和 Total basal area & 0.594 & 69.1 & $1,097.032$ & 0.000 & 1.312 & 0.256 \\
\hline
\end{tabular}

$P_{r}(F)$ 指对本行模型与上一行模型进行离差分析时 $F$ 检验所获得的值; $P_{\mathrm{r}}(\chi)$ 表示对非参数平滑效果的非线性贡献检验得分, 其值越小效果越好。

$P_{r}(F)$ referred to the $p$-value from an ANOVA F-ration test between the model for that row and the model for the previous row. $P_{\mathrm{r}}(\chi)$ represented a type of score test to evaluate the non-linear contribution of non-parametric effects, and the lowest value meant the best.

调落量多年间的节律性存在明显差异, 包含了双 峰、三峰甚至多峰型。多年连续监测表明, 弄岗喀 斯特季节性雨林调落物年均调落量的季节性动态 总体表现为明显的双峰型, 即分别为每年的生长季 开始前(3-4月)和生长季结束后(9-11月)。这一规律 与当地的气候有关。弄岗国家级自然保护区地处北 热带季风性气候区, 雨季和旱季区分明显, 雨季主 要集中在每年的5-9月, 而旱季则主要在每年的 10 月至翌年的4月(Guo et al, 2018)。这一结论与茂兰中 亚热带喀斯特森林调落物的调落节律基本一致, 但 调落期要滞后 1-2个月(5月和10-12月达到峰值) (俞 国松等, 2011)。这可能是因为地处北热带的弄岗喀 斯特季节性雨林要比处于中亚热带的茂兰阔叶混 交林更早进入展叶期, 相应地, 常绿物种较早进入 落叶期以备后期展叶。

局域尺度上, 海拔是影响调落量的重要因子。 一般而言, 森林调落量随海拔的升高而减少 (Reiners \& Lang, 1987)。然而, 在弄岗喀斯特季节性 雨林180-370 m海拔范围内叶调落量与海拔呈正相 关关系, 即叶片的调落量随着海拔的升高而增加, 且海拔是影响调落量的第一要素。这可能是由三方 面的原因造成: (1)洼地及其周边湿润生境中, 经常 存在季节性水淹, 因此土壤含氧量往往较低, 从而 限制了直立木本植物的生长; (2)未将广布于洼地及 周边湿润生境中的木质藤本植物的调落叶纳入到 研究对象中; (3)未将海拔高、地势陡峭、土壤稀少、 植被稀疏且以旱生型山顶矮林为主的峰顶包括在
内。坡度、凹凸度和干旱度指数与叶片调落量年际 动态均存在显著正相关, 而湿润度指数则与叶调落 量年际动态存在显著负相关。喀斯特季节性雨林中, 海拔是影响其他环境因子的主要因素, 如海拔越高, 地势越陡峭, 岩石裸露率越高, 土壤越干旱。因此, 不同环境因子间往往表现出显著相关性或存在共 线性问题(Guo et al, 2017, 2019)。

与环境因子相比, 生物因子对调落量的作用相 对较弱, 仅单位面积胸高断面积之和与调落量表现 出较强的相关性。生物多样性与生产力常表现出一 定的相关性，如物种多样性促进生产力的提高 (Poorter et al, 2015), 林层结构的多样性(胸径变异 系数)也可以促进生产力的提高(Zhang \& Chen, 2015)。然而, 喀斯特季节性雨林中物种多样性与调 落量仅表现出较弱的正相关性，而林层结构的多样 性与调落量表现出较强的负相关性，而且其对调落 量的解释率较低。这可能是由于林层结构的复杂性 导致主林层(林冠层)的调落物被下层阻挡, 减少了 调落物收集器的收集量。这一结论与Guo等(2019) 运用结构方程探讨调落物的形成机制得出的结论 相似。这可能是因为喀斯特地质背景下，以海拔为 主的环境因子是形成水分梯度、土层厚度和土量、 土壤营养梯度等的主要原因, 进而影响了喀斯特环 境中的生物因子, 如物种多样性、群落结构和初级 生产力等。比如, 海拔也是影响喀斯特季节性雨林 单位面积胸高断面积之和分布格局的主要因素，二 者呈显著正相关关系(郭屹立等, 2016)。 
北热带喀斯特季节性雨林中具有非常高的藤 本植物丰富度, 且主要分布于洼地及其周边较为湿 润的生境中(蒋裕良等, 2017)。藤本植物对森林群落 结构与动态起着非常重要而复杂的作用。藤本植物 也能通过竞争或直接的机械损伤显著地减缓树木 的生长并增加树木的死亡(Ingwell et al, 2010), 进而 影响森林的生产力与生长量。藤本植物尤其是木质 藤本植物本身亦是森林生态系统的重要组成部分, 其自身的生产力和碳储量在喀斯特季节性雨林中 可能占有重要作用。在喀斯特季节性雨林洼地及周 边湿润的生境中, 直立木本植物往往被木质藤本植 物所覆盖, 而这些生境中木质藤本植物的生产力和 碳储量可能远高于直立木本植物。然而, 依据CTFS 样地建设标准, 木质藤本植物未被纳入调查与监测 范围, 而且目前有关木质藤本植物的调查与监测仍 然没有统一的标准。目前, 弄岗15 ha森林动态监测样 地已经开始尝试通过一定的方法来加强对木质藤 本植物的监测, 以期为进一步揭示北热带喀斯特季 节性雨林的净初级生产力和碳储量提供准确依据。

致谢: 感谢广西弄岗国家级自然保护区管理局提供 帮助; 感谢崇左市龙州县逐卜乡楞垒屯苏理生、坡 那屯黄春协助收集调落物。

\section{参考文献}

Burnham KP, Anderson DR (2002) Model Selection and Multimodel Inference: A Practical Information-Theoretic Approach, 2nd edn. Springer, New York.

Cao KF, Fu PL, Chen YJ, Jiang YJ, Zhu SD (2014) Implications of the ecophysiological adaptation of plants on tropical karst habitats for the ecological restoration of desertified rocky lands in southern China. Scientia Sinica Vitae, 44, 238-247. (in Chinese with English abstract) [曹坤芳, 付培 立, 陈亚军, 姜艳娟, 朱师丹 (2014) 热带岩溶植物生理 生态适应性对于南方石漠化土地生态重建的启示. 中国 科学: 生命科学, 44, 238-247.]

Condit R (1998) Tropical Forest Census Plots: Methods and Results from Barro Colorado Island, Panama and A Comparison with Other Plots. Springer, Berlin.

Du YJ, Mi XC, Liu XJ, Chen L, Ma KP (2009) Seed dispersal phenology and dispersal syndromes in a subtropical broad-leaved forest of China. Forest Ecology and Management, 258, 1147-1152.

Guan LL, Zhou GY, Zhang DQ, Liu JX, Zhang QM (2004) Twenty years of litter fall dynamics in subtropical evergreen broad-leaved forests at the Dinghushan Forest Ecosystem
Research Station. Acta Phytoecologica Sinica, 28, 449-456. (in Chinese with English abstract) [官丽莉, 周国逸, 张德 强, 刘菊秀, 张倩媚 (2004) 鼎湖山南亚热带常绿阔叶林 调落物量20年动态研究. 植物生态学报, 28, 449-456.]

Guisan A, Edwards Jr TC, Hastie T (2002) Generalized linear and generalized additive models in studies of species distributions: Setting the scene. Ecological Modelling, 157, 89-100.

Guo K, Liu CC, Dong M (2011) Ecological adaptation of plants and control of rocky-desertification on karst region of Southwest China. Chinese Journal of Plant Ecology, 35, 991999. (in Chinese with English abstract) [郭柯, 刘长成, 董 鸣 (2011) 我国西南喀斯特植物生态适应性与石漠化治 理. 植物生态学报, 35, 991-999.]

Guo LB, Sims REH (1999) Litter production and nutrient return in New Zealand eucalypt short-rotation forest: Implications for land management. Agriculture Ecosystems \& Environment, 73, 93-100.

Guo YL, Chen HYC, Mallik AU, Wang B, Li DX, Xiang WS, Li XK (2019) Predominance of abiotic drivers in the relationship between species diversity and litterfall production in a tropical karst seasonal rainforest. Forest Ecology and Management, 449, 117452.

Guo YL, Li DX, Wang B, He YL, Xiang WS, Jiang YL, Li XK (2017) Composition and spatio-temporal dynamics of litter fall in a northern tropical karst seasonal rainforest in Nonggang, Guangxi, southern China. Biodiversity Science, 25, 265-274. (in Chinese with English abstract) [郭屹立, 李冬 兴, 王斌, 何运林, 向悟生, 蒋裕良, 李先琨 (2017) 北 热带喀斯特季节性雨林调落物组分构成及时空动态特征. 生物多样性, 25, 265-274.]

Guo YL, Wang B, Li DX, Mallik AU, Xiang WS, Ding T, Wen SJ, Lu SH, Huang FZ, He YL, Li XK (2017) Effects of topography and spatial processes on structuring tree species composition in a diverse heterogeneous tropical karst seasonal rainforest. Flora, 231, 21-28.

Guo YL, Wang B, Xiang WS, Ding T, Lu SH, Huang FZ, Wen SJ, Li DX, He YL, Li XK (2016) Responses of spatial pattern of woody plants' basal area to topographic factors in a tropical karst seasonal rainforest in Nonggang, Guangxi, southern China. Biodiversity Science, 24, 30-39. (in Chinese with English abstract) [郭屹立, 王斌, 向悟生, 丁涛, 陆树华, 黄甫昭, 文淑均, 李冬兴, 何运林, 李先琨 (2016) 喀斯特季节性雨林木本植物胸高断面积分布格局 及其对地形因子的响应. 生物多样性, 24, 30-39.]

Guo YL, Wang B, Xiang WS, Ding T, Lu SH, Huang YS, Huang FZ, Li DX, Li XK (2015) Spatial distribution of tree species in a tropical karst seasonal rainforest in Nonggang, Guangxi, southern China. Biodiversity Science, 23, 183-191. (in Chinese with English abstract) [郭屹立, 王斌, 向悟生, 丁涛，陆树华，黄俞淞，黄甫昭，李冬兴，李先琨 (2015) 广西弄岗北热带喀斯特季节性雨林监测样地种群空间点 格局分析. 生物多样性, 23, 183-191.]

Guo YL, Xiang WS, Wang B, Li DX, Mallik AU, Chen HYC, Huang FZ, Ding T, Wen SJ, Lu SH, Li XK (2018) 
Partitioning beta diversity in a tropical karst seasonal rainforest in Southern China. Scientific Reports, 8, 17408.

Han XY, Zhao FX, Li WY (2007) A review of researches on forest litterfall. Forestry Science and Technology Information, 39, 12-13, 16.

Ingwell LL,Wright JS, Becklund KK, Hubbell SP, Schnitzer SA (2010) The impact of lianas on 10 years of tree growth and mortality on Barro Colorado Island, Panama. Journal of Ecology, 98, 879-887.

Jiang YL, Li XK, Guo YL, Ding T, Wang B, Xiang WS (2017) Diversity of climbing seed plants and their reproductive habit in a karst seasonal rain forest in Nonggang, Guangxi, China. Chinese Journal of Plant Ecology, 41, 716-728. (in Chinese with English abstract) [蒋裕良, 李先琨, 郭屹立, 丁涛, 王斌, 向悟生 (2017) 广西弄岗喀斯特季节性雨林 藤本种子植物多样性及繁殖习性. 植物生态学报, 41, 716-728.]

Jiang ZC, Yuan DX (1999) Dynamics features of the epikarst zone and their significance in environment sand resources. Acta Geoscientica Sinica, 20, 302-308. (in Chinese with English abstract) [蒋忠诚, 袁道先 (1999) 表层岩溶带的 岩溶动力学特征及其环境和资源意义. 地球学报, 20 , 302-308.]

Li XK, He CX, Tang JS, Jiang ZC, Huang YQ (2008) Evolution and ecological processes of karst ecosystem of Guangxi. Guangxi Sciences, 15, 80-86, 91. (in Chinese with English abstract) [李先琨, 何成新, 唐建生, 蒋忠诚, 黄玉清 (2008) 广西岩溶山地生态系统特征与恢复重建. 广西科 学, 15, 80-86, 91.]

Liu CJ, Westman CJ, Berg B, Kutsch W, Wang GZ, Man RZ, Ilvesniemi H (2004) Variation in litterfall-climate relationships between coniferous and broadleaf forests in Eurasia. Global Ecology and Biogeography, 13, 105-114.

Malhi Y (2012) The productivity, metabolism and carbon cycle of tropical forest vegetation. Journal of Ecology, 100, 65-75.

Poorter L, van der Sande MT, Thompson J, Arets EJMM, Alarcón A, Álvarez-Sánchez J, Ascarrunz N, Balvanera P, Barajas-Guzmán G, Boit A, Bongers F, Carvalho FA, Casanoves F, Cornejo-Tenorio G, Costa FRC, de Castilho CV, Duivenvoorden JF, Dutrieux LP, Enquist BJ, Fernández Méndez F, Finegan B, Gormley LHL, Healey JR, Hoosbeek MR, Ibarra-Manríquez G, Junqueira AB, Levis C, Licona JC, Lisboa LS, Magnusson WE, Martínez-Ramos M, Martínez-Yrizar A, Martorano LG, Maskell LC, Mazzei L, Meave JA, Mora F, Muñoz R, Nytch C, Pansonato MP, Parr TW, Paz H, Pérez-García EA, Rentería LY, RodríguezVelazquez J, Rozendaal DMA, Ruschel AR, Sakschewski B, Salgado-Negret B, Schietti J, Simões M, Sinclair FL, Souza PF, Souza FC, Stropp J, ter Steege H, Swenson NG, Thonicke K, Toledo M, Uriarte M, van der Hout P, Walker P, Zamora N, Peña-Claros M (2015) Diversity enhances carbon storage in tropical forests. Global Ecology and Biogeography, 24, 1314-1328.

R Core Team (2019) R: A language and environment for stati- stical computing. R Foundation for Statistical Computing, Vienna. https://www.R-project.org/. (accessed on 2019-11-15)

Reiners WA, Lang GE (1987) Changes in litterfall along a gradient in altitude. Journal of Ecology, 5, 629-638.

Sharma S, Hoque ATMR, Analuddin K, Hagihara A (2012) Litterfall dynamics in an overcrowded mangrove Kandelia obovata (S., L.) Yong stand over five years. Estuarine Coastal and Shelf Science, 98, 31-41.

Swartzman G, Huang CH, Kaluzny S (1992) Spatial analysis of Bering Sea groundfish survey data using generalized additive models. Canadian Journal of Fisheries and Aquatic Sciences, 49, 1366-1378.

Vasconcelos HL, Luizão FJ (2004) Litter production and litter nutrient concentrations in a fragmented Amazonian landscape. Ecological Applications, 14, 884-892.

Wang B, Huang YS, Li XK, Xiang WS, Ding T, Huang FZ, Lu SH, Han WH, Wen SJ, He LJ (2014) Species composition and spatial distribution of the 15 ha northern tropical karst seasonal rain forest dynamic plot in Nonggang of Guangxi, southern China. Biodiversity Science, 22, 141-156. (in Chinese with English abstract) [王斌, 黄俞淞, 李先琨, 向 悟生, 丁涛, 黄甫昭, 陆树华, 韩文衡, 文淑均, 何兰军 (2014) 弄岗北热带喀斯特季节性雨林15 ha监测样地的树 种组成与空间分布. 生物多样性, 22, 141-156.]

Wang FY (1989) Review on the study of forest litterfall. Advances in Ecology, 6(2), 82-89. (in Chinese with English abstract) [王凤友 (1989) 森林调落量研究综述. 生态学 进展, 6(2), 82-89.]

Wood SN (2006) Generalized Additive Models: An Introduction with R. Chapman and Hall/CRC Press, London.

Yan ER, Wang XH, Zhou W (2008) Characteristics of litterfall in relation to soil nutrients in mature and degraded evergreen broad-leaved forests of Tiantong, East China. Journal of Plant Ecology (Chinese Version), 32, 1-12. (in Chinese with English abstract) [阎恩荣, 王希华, 周武 (2008) 天 童常绿阔叶林演替系列植物群落的 $\mathrm{N}$ : $\mathrm{P}$ 化学计量特征. 植 物生态学报, 32, 1-12.]

Yu GS, Wang SJ, Rong L, Ran JC (2011) Litter dynamics of major successional communities in Maolan karst forest of China. Chinese Journal of Plant Ecology, 35, 1019-1028. (in Chinese with English abstract) [俞国松, 王世杰, 容丽, 再 景丞 (2011) 茂兰喀斯特森林主要演替群落的调落物动 态. 植物生态学报, 35, 1019-1028.]

Yuan DX (1991) Karst of China. Geological Publishing House, Beijing.

Zhang H, Yuan W, Dong W, Liu S (2014) Seasonal patterns of litterfall in forest ecosystem worldwide. Ecological Complexity, 20, 240-247.

Zhang Y, Chen HYH (2015) Individual size in equality links forest diversity and above-ground biomass. Journal of Ecology, 103, 1245-1252.

(责任编委：林露湘＼cjkstart责任编辑：黄祥忠) 